\title{
The Usefulness of Intrapartum Transperineal Ultrasonography for the Prediction of Mode of Delivery
}

\section{Erdinc SARIDOGAN1, Ozlem MORALOGLU TEKIN²}

Tunceli, Turkey

\begin{abstract}
OBJECTIVE: We aimed to assess the accuracy of intrapartum transperineal ultrasonography that is non-invasive, easy to learn, rapid to perform, comfortable for pregnant women, and low-cost method to evaluate the progress of labor objectively.

STUDY DESIGN: We evaluated two hundred-ten singleton pregnant women at term with cephalic presentation who went into active labor via intrapartum transperineal ultrasonography using the angle of progression and head-perineum distance. Maternal characteristics, conventional vaginal examination findings, mode of delivery, and neonatal results were noted. The data were compared using correlation and regression analysis.
\end{abstract}

RESULTS: The relationships between the descent of clinical fetal head station, the increase of angle of progression $(p=0.001)$, and the decrease of head-perineum distance $(p=0.001)$ were statistically significant. The receiver operating characteristics curve showed that measurement of angle of progression with $<110.5$ degrees $(p=0.001)$ and measurement of head-perineum distance with $>52.5$ millimeters $(p=0.001)$ were associated with emergent cesarean delivery. For the prediction of delivery mode, both angle of progression and head-perineum distance had high sensitivity and specificity.

CONCLUSIONS: Intrapartum transperineal ultrasonography parameters were in agreement with each other and conventional vaginal examination for determination of delivery mode. Head-perineum distance was a parity-dependent measurement whilst angle of progression was parity-independent.

Keywords: Angle of progression, Delivery, Head-perineum distance, Labor, Transperineal ultrasound

Gynecol Obstet Reprod Med 2021;27(2):116-122

\section{Introduction}

Traditional vaginal examination together with intermittent maternal and fetal monitoring is still the mainstay of monitoring labor in low-risk pregnancies. There is a significant variation between obstetricians' evaluation of the position and the level of the fetal head, the diameter of maternal pelvis, and di-

${ }^{1}$ Department of Obstetrics and Gynecology, Tunceli State Hospital, Tunceli, Turkey.

${ }^{2}$ Department of Obstetrics and Gynecology, University of Health Sciences, Ankara City Hospital, Ankara, Turkey

Address of Correspondence: Erdinc Saridogan

Cumhuriyet District, Street 203, 25/3,

Tunceli State Hospital, 62000 Tunceli, Turkey erdincsaridogan@hotmail.com

Submitted for Publication: 06.10.2019 Revised for Publication: 07.05.2020

Accepted for Publication: 05.06.2020 Online Published: 02.08.2021

ORCID IDs of the authors: ES: 0000-0003-2183-7689

OMT: 0000-0001-8167-3837

\begin{tabular}{|c|c|}
\hline \multirow{3}{*}{ 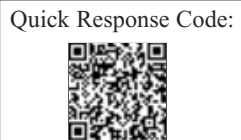 } & Access this article online \\
\hline & $\begin{array}{l}\text { Website: www.gorm.com.tr } \\
\text { e- mail: info@gorm.com.tr }\end{array}$ \\
\hline & DOI:10.21613/GORM.2020.1031 \\
\hline
\end{tabular}

How to cite this article: Saridogan E. and Moraloglu Tekin O. The Usefulness of Intrapartum Transperineal Ultrasonography for the Prediction of Mode of Delivery. Gynecol Obstet Reprod Med. 2021;27(2):116-122 latation and effacement of the cervix. This has lead researchers to explore more objective methods for the management of labor. There is no evidence of the usefulness of pelvimetry except clinical pelvimetry due to various factors such as uterine activity, relaxation of maternal pelvis, and molding of the fetal head. Also, indications for pelvimetry are limited due to the detrimental effects of X-ray and low speed and high cost of magnetic resonance imaging. In contrast, intrapartum sonography which is a non-invasive, easy to learn, rapid to perform, comfortable for pregnant women, and low-cost method has become popular for the monitoring of labor. Measurement of head-perineum distance (HPD) was first reported (1) and followed by the angle of progression (AOP) $(2,3)$. Their consistency with the clinical fetal head station (CFHS) and success of prediction the delivery mode was reported. In our study, we aimed to assess whether AOP and HPD correlate with each other and CFHS and they predict the mode of delivery.

\section{Material and Method}

In this investigation, two hundred and ten singleton pregnant women who went into active labor at term with cephalic presentation and ruptured membranes were recruited. The study was performed at the University of Health Sciences, 
Zekai Tahir Burak Women Health Education and Research Hospital in Ankara Turkey between January of 2015 and January of 2017 after having obtained the approval of our hospital's research ethics committee (number and date of decision are 11 and 29.12.2014, respectively). It was conducted under the principles set in the Helsinki Declaration (as revised in Fortaleza, Brazil, October 2013). Informed consent was obtained from all pregnant women before the intrapartum evaluation was performed. Active labor was demonstrated by at least regular three uterine contractions that reached 200-250 Montevideo units in total in ten minutes and cervical dilatation of 5-6 cm (4). Pregnant women who were administered epidural anesthesia or with the non-cephalic presentation had any concomitant systemic disease, suspicion of chorioamnionitis, non-reassuring fetal status, multiple gestations or previous cesarean delivery (CD) were not included in the research.

Maternal characteristics such as age, obstetric history, gestational age (weeks) according to the last menstrual period, and body mass index were noted. Ultrasonographic measurements were taken by a single operator using the TOSHIBA Aplio MX (SSA-780A, Japan) ultrasound machine.

Intrapartum transperineal ultrasonography (ITU) was performed in lithotomy position with empty bladder using a glove covered abdominal probe on sagittal and transverse images between the inferior edge of the pubic symphysis and the labia. AOP which is the angle between the long axis of the pubic symphysis and the leading part of the fetal skull was measured at the midsagittal plane as described before (2) (Figure 1a). HPD which is the distance between the leading portion of the fetal skull and the perineum was measured by pressing the ultrasound transducer without disturbing pregnant woman on the transverse view as defined before (1) (Figure 1b).

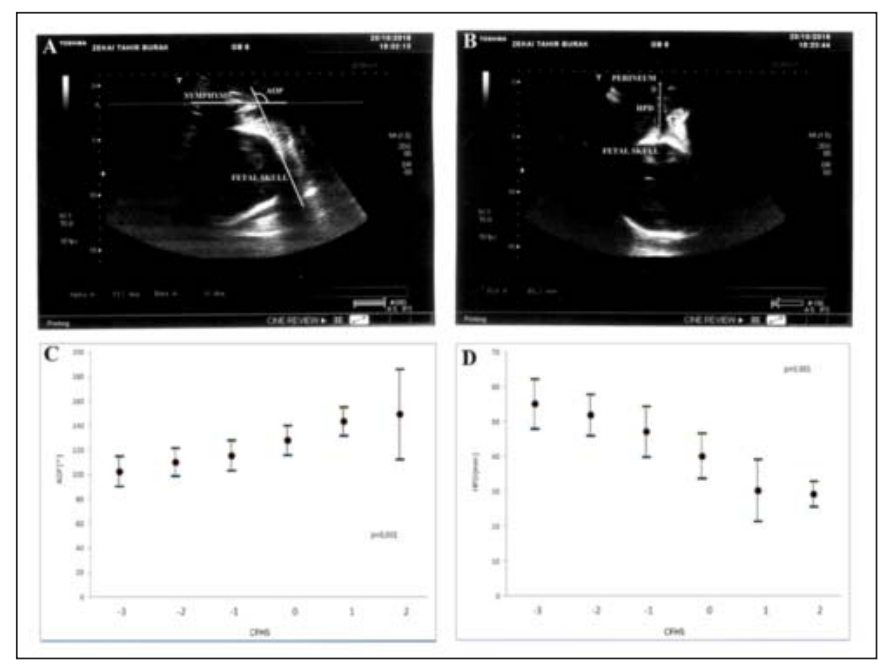

Figure 1a: Measurement of angle of progression, b: Measurement of head-perineum distance, c: The interaction between clinical fetal head station and angle of progression d: The interaction between clinical fetal head station and headperineum distance
Intrapartum transperineal ultrasonography parameters were gauged three times per pregnant woman in a minute and averages were recorded. Immediately afterward, the traditional vaginal examination was performed by a different clinician. Dilatation and effacement of the cervix and fetal head station according to the classification of the ischial spine from $(-5)$ to $(+5)$ were enrolled. However, there were no women at -5 and -4 levels. This may be because the study was performed in women under active labor. Also, there were no women at +4 and +5 levels owing to being technically difficult of applying transperineal ultrasonography at those levels.

Teams performing ITU and vaginal examinations were blinded to the assessments of each other. Decisions about labor were made solely by the vaginal examination team. Fundal pressure was not applied to any of the women in the first and second stages of labor. Mode of delivery, the weight of the newborn, and Apgar scores were recorded after delivery.

Statistical analysis was performed by using Statistical Package for the Social Sciences version 11.5 (SPSS, Inc., Chicago, IL.). By using the values in the study of Chan et al (5), we calculated with $90 \%$ power and 5\% Type I error that our sample should include a minimum of 160 pregnant women $(\mathrm{R}$ 3.0.1. open-source program). Additionally, our power analysis forecasted that there may be a deviation of $\pm 5 \%$ from the average. Descriptive statistics were presented as mean $( \pm$ standard deviation), median (range), and percent. The relationship between CFHS, AOP, and HPD was evaluated by using one-way analysis of variance (ANOVA). Bonferroni which is one of the Post-hoc tests was utilized to determine the difference between the groups. The correlation between the AOP and HPD was studied with the Pearson product-moment correlation coefficient and linear regression analysis. The predictability of mode of delivery was performed by AOP and HPD which were analyzed using Independent Samples T-Test, and by CFHS which was analyzed using the Mann-Whitney U Test. AOP and HPD's cut off values for prediction of the mode of delivery were calculated by Receiver Operating Characteristics (ROC) curve. Pearson's chi-squared test was performed to find the Odds Ratio (OR) with 95\% Confidence Interval (CI). $p<0.05$ was regarded as statistically significant for all statistics.

\section{Results}

One hundred-five nulliparous and one hundred-five multiparous pregnant women in active labor were recruited. One hundred eighty-eight women $(89.5 \%)$ had a vaginal delivery (VD). Twenty-two women (10.5\%) had CD due to cephalopelvic disproportion $(\mathrm{n}=17)$ and failure to progress in active labor $(\mathrm{n}=5)$. Oxytocin infusion was applied to $60.9 \%$ $(128 / 210)$ of pregnant women. This rate was $81.8 \%$ of pregnant women who had CD (18/22). The descriptive characteristics of pregnant women and newborns are shown in table I.

Descriptive characteristics of $\mathrm{VD}$ and $\mathrm{CD}$ groups are shown in table II. 
Table I: Descriptive characteristics of pregnant women and newborns

\begin{tabular}{|c|c|c|c|c|}
\hline Characteristics & Mean, $\mathrm{n}^{*}$ or Median** & Standard deviation & Range & Percent (\%) \\
\hline Age (years) & 26.6 & \pm 5.77 & $16-43$ & \\
\hline \multicolumn{5}{|l|}{ Parity } \\
\hline 0 & $105^{*}$ & & & 50 \\
\hline$\geq 1$ & $105^{*}$ & & & 50 \\
\hline Gestational age (weeks) & 39.2 & \pm 1.21 & $37+0-41+6$ & \\
\hline BMI $\left(\mathrm{kg} / \mathrm{m}^{2}\right)$ & 28.33 & \pm 4.15 & $18.2-46$ & \\
\hline AOP (degrees) & 119.13 & \pm 16.03 & $75-176$ & \\
\hline HPD (mm) & 46.13 & \pm 9.53 & $21.8-69$ & \\
\hline VD & $188^{*}$ & & & 89.5 \\
\hline$C D$ & $22^{*}$ & & & 10.5 \\
\hline Weight of newborns (grams) & 3263.97 & \pm 389.66 & $2250-4780$ & \\
\hline $1^{\text {st }}$ minute APGAR score & $8^{* *}$ & & 4-9 & \\
\hline $5^{\text {th }}$ minute APGAR score & $10^{* *}$ & & $7-10$ & \\
\hline
\end{tabular}

n: Number, BMI: Body mass index, kg: Kilogram, m: Meter, mm: Millimeters, AOP: Angle of progression, HPD: Head-perineum distance, VD: Vaginal delivery, $C D$ : Cesarean delivery

Table II: Descriptive characteristics of vaginal delivery and cesarean delivery groups

\begin{tabular}{|c|c|c|c|c|}
\hline Characteristics & Mean, $\mathrm{n}^{*}$ or Percent ${ }^{* *}$ & Standard deviation & Range & $p$ \\
\hline \multicolumn{5}{|l|}{ Age (years) } \\
\hline VD & 26.7 & 5.8 & $16-41$ & 0.388 \\
\hline$C D$ & 25.6 & 5.7 & $18-43$ & \\
\hline \multicolumn{5}{|l|}{ Parity $=0$} \\
\hline VD & $86^{*}\left(\% 81.9^{* *}\right)$ & & & \\
\hline$C D$ & $19^{*}\left(\% 18.1^{* *}\right)$ & & & \\
\hline \multicolumn{5}{|l|}{ Parity $\geq 1$} \\
\hline VD & $59^{*}\left(\% 96.7^{* *}\right)$ & & & \\
\hline$C D$ & $2^{*}\left(\% 3.3^{* *}\right)$ & & & \\
\hline \multicolumn{5}{|c|}{ Gestational age (weeks) } \\
\hline VD & 39.2 & 1.2 & $37-41.4$ & 0.969 \\
\hline$C D$ & 39.2 & 1.5 & $37-41.6$ & \\
\hline \multicolumn{5}{|l|}{ BMI $\left(\mathrm{kg} / \mathrm{m}^{2}\right)$} \\
\hline VD & 28.2 & 4.1 & $18.2-46$ & 0.071 \\
\hline CD & 29.8 & 4.4 & $22.8-42.6$ & \\
\hline \multicolumn{5}{|l|}{ AOP (degrees) } \\
\hline VD & 120.67 & 15.5 & 88-176 & $<0.001$ \\
\hline$C D$ & 106.04 & 14.7 & $75-138$ & \\
\hline \multicolumn{5}{|l|}{ HPD (mm) } \\
\hline VD & 45.28 & 9.3 & $21.8-64.8$ & $<0.001$ \\
\hline$C D$ & 53.36 & 8.3 & $30.9-69$ & \\
\hline \multicolumn{5}{|c|}{ AOP (degrees) at 0} \\
\hline VD & 128.8 & 11.9 & $111-170$ & $<0.001$ \\
\hline CD & 117.5 & 0.7 & $117-118$ & \\
\hline \multicolumn{5}{|l|}{$\mathrm{HPD}(\mathrm{mm})$ at 0} \\
\hline VD & 40.2 & 6.2 & $24-54$ & 0.849 \\
\hline CD & 43.2 & 17.3 & $30.9-55.5$ & \\
\hline \multicolumn{5}{|c|}{ Weight of newborns (grams) } \\
\hline VD & 3246.7 & 375.5 & $2250-4270$ & 0.060 \\
\hline$C D$ & 3411.6 & 479.7 & $2500-4780$ & \\
\hline \multicolumn{5}{|c|}{$1^{\text {st }}$ minute Apgar score } \\
\hline VD & 7.9 & 0.5 & $4-8$ & 0.004 \\
\hline CD & 8.5 & 0.9 & $6-9$ & \\
\hline \multicolumn{5}{|c|}{$5^{\text {th }}$ minute APGAR score } \\
\hline VD & 9.9 & 0.4 & $7-10$ & 0.523 \\
\hline$C D$ & 9.8 & 0.5 & $8-10$ & \\
\hline
\end{tabular}

n: Number, BMI: body mass index, kg: kilogram, m: meter, mm: millimeters, AOP: angle of progression, HPD: head - perineum distance, VD: vaginal delivery, $C D$ : cesarean delivery 
Angle of progressionand HPD were able to predict the mode of delivery $(\mathrm{p}<0.001$ for both). The mean AOP of women who had VD was $120.67 \pm 15.5$ degrees. On the other hand, the mean AOP of women who had CD was 106.04 \pm 14.7 degrees $(p<0.001)$. The mean HPD of women who had VD was 45.28 $\pm 9.32 \mathrm{~mm}$. Nevertheless, the mean HPD of women who had $\mathrm{CD}$ was $53.36 \pm 8.33(\mathrm{p}<0.001)$. Moreover, AOP and HPD values between the groups at 0 of CFHS are also stated in table II. AOP was significantly different between VD and CD groups at 0 , whereas the difference in HPD was insignificant.

The correlation between CFHS and the mode of delivery was significant $(\mathrm{p}=0.001)$. The median value of CFHS in pregnant women who had VD was -1 (ranged from -3 to +2 ). The median value of CFHS in pregnant women who had CD was -2 (ranged from -3 to 0 ).

The relationships between CFHS and AOP $(p=0.001)$ or HPD $(p=0.001)$ were significant (Figure $1 \mathrm{c}$ and $1 \mathrm{~d}$, respec- tively). According to CFHS, changes in AOP and HPD are shown in table III. The decrease of AOP compared to the increase of HPD was significant $(r=0.64, p=0.001)$. Figure $2 \mathrm{a}$ demonstrated that a millimeter increase of HPD corresponded to a 1.054-degree decrease of AOP. ROC analyzes which shown in figure $2 \mathrm{~b}$ and $2 \mathrm{c}$ indicated that $\geq 110.5$ degrees of AOP (AUC $=0.766, p=0.001)$ and $\leq 52.45$ millimeters of HPD (AUC $=0.747, p=0.001$ ) were meaningful for the prediction of delivery mode, respectively.

The methodological results are shown in table IV. If cut off value of AOP is taken as 110.5 degrees; sensitivity was $74.5 \%$, specificity was $72.7 \%$, negative predictive value (NPV) was 95.8\%, positive predictive value (PPV) was $25 \%$ and Odds Ratio (OR) is 7.778 [ $p=0.001$, (95\% CI 2.879-21.013)]. If cut off value of HPD was taken as 52.45 millimeters; sensitivity was $77.1 \%$, specificity was $72.7 \%$, NPV was $96 \%$, PPV was $27.1 \%$ and OR was 8.992 [ $p=0.001$, (95\% CI 3.314-24.397)].

Table III: Relationship of angle of progression and head-perineum distance with clinical fetal head station and parity

\begin{tabular}{lccc}
\hline CFHS & $\mathrm{n}$ & AOP (mean degrees) & HPD (mean mm) \\
\hline-3 & 18 & $103.16 \pm 12.33$ & $55.36 \pm 7.2$ \\
-2 & 55 & $110.96 \pm 11.21$ & $52.13 \pm 6$ \\
-1 & 64 & $116.15 \pm 12.19$ & $47.33 \pm 7.38$ \\
0 & 58 & $128.44 \pm 11.9$ & $40.32 \pm 6.55$ \\
+1 & 13 & $144.23 \pm 11.58$ & $30.47 \pm 8.93$ \\
+2 & 2 & $150 \pm 36.76$ & $29.4 \pm 3.67$ \\
Parity & & & $44.53 \pm 9.95$ \\
0 & & & $47.72 \pm 8.86$ \\
\hline 1
\end{tabular}

${ }^{*}$ Independent Samples $t$-Test was used. $p<0.05$ was accepted for statistically significant

AOP: Angle of progression, HPD: Head-perineum distance, CFHS: Clinical fetal head station, $n$ : Number, mm: Millimeters

Table IV: Sensitivity, specificity, negative predictive value, positive predictive value, and odds ratio for angle of progression and head- perineum distance's prediction of the mode of delivery

\begin{tabular}{|c|c|c|c|c|c|}
\hline & & & \multicolumn{2}{|c|}{ Mode of delivery } & \multirow[t]{2}{*}{ Total } \\
\hline & & & VD & $C D$ & \\
\hline \multirow[t]{4}{*}{ AOP (degrees) } & $\geq 110.5$ & $\mathrm{n}$ & 140 & 6 & 146 \\
\hline & $\geq 110.5$ & Percent & $74.5 \% *$ & $27.3 \%$ & $69.5 \%$ \\
\hline & $<110.5$ & $\mathrm{n}$ & 48 & 16 & 64 \\
\hline & $<110.5$ & Percent & $25.5 \%$ & $72.7 \%$ ** & $30.5 \%$ \\
\hline \multirow[t]{2}{*}{ Total } & & $\mathrm{n}$ & 188 & 22 & 210 \\
\hline & & Percent & $100 \%$ & $100 \%$ & $100 \%$ \\
\hline
\end{tabular}

*Sensitivity, **Specificity, NPV=95.8\%, PPV=25\%, OR=7.778 (95\% Cl 2.879-21.013)***

${ }^{* * *}$ Pearson's Chi-squared test was performed. $p<0.05$ was accepted for statistically significant

\begin{tabular}{|c|c|c|c|c|c|}
\hline \multirow[t]{4}{*}{ HPD (mm) } & $\leq 52.45$ & $\mathrm{n}$ & 145 & 6 & 151 \\
\hline & $\leq 52.45$ & Percent & $77.1 \%$ * & $27.3 \%$ & $71.9 \%$ \\
\hline & $>52.45$ & $\mathrm{n}$ & 43 & 16 & 59 \\
\hline & $>52.45$ & Percent & $22.9 \%$ & $72.7 \%$ ** & $28.1 \%$ \\
\hline \multirow[t]{2}{*}{ Total } & & $\mathrm{n}$ & 188 & 22 & 210 \\
\hline & & Percent & $100 \%$ & $100 \%$ & $100 \%$ \\
\hline
\end{tabular}

*Sensitivity, ** Specificity, NPV=96\%, PPV=27.1\%, OR=8.992 (95\% Cl 3.314-24.397)***

${ }^{* * *}$ Pearson's Chi-squared test was performed. $p<0.05$ was accepted for statistically significant

AOP: angle of progression, $n$ : Number, VD: vaginal delivery, CD: cesarean delivery, NPV: negative predictive value, PPV: positive predictive value,

OR: odds ratio, $\mathrm{Cl}$ : confidence interval, HPD: head-perineum distance, $\mathrm{mm}$ : millimeters 


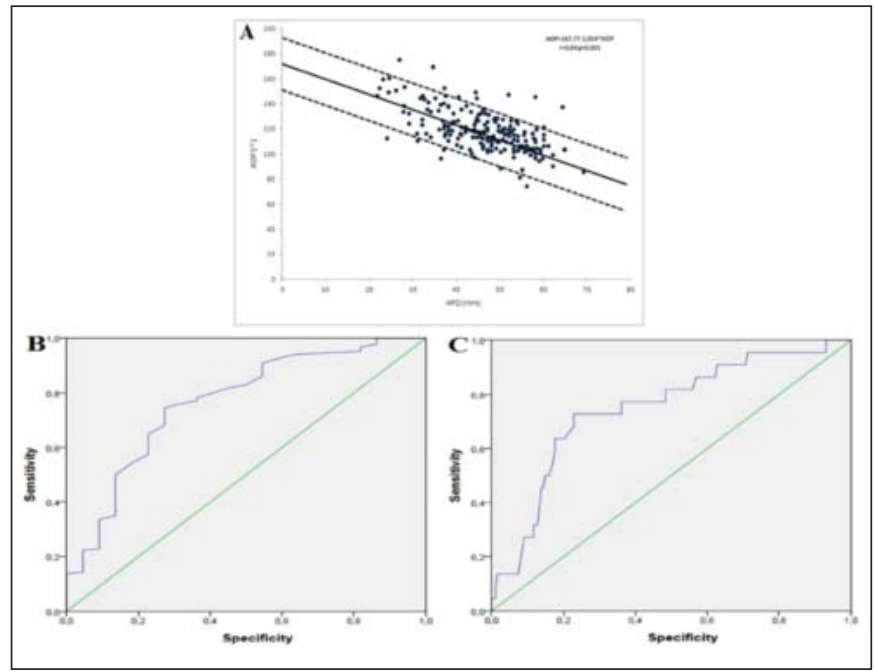

Figure 2a: The relation between angle of progression and head-perineum distance, $\boldsymbol{b}$ : Receiver operating characteristics analysis of angle of progression, c: Receiver operating characteristics analysis of head-perineum distance

\section{Discussion}

Intrapartum ultrasonography was first performed to find out the incidence of the persistence of occiput posterior position by Gardberg et al in 1998 (6). It was reported that intrapartum sonography could be performed to evaluate the engagement of the fetal head $(7,8)$. After the definition and demonstration of accuracy and reproducibility of AOP, it was considered that a cut off value of 120 degrees might predict the vaginal delivery $(2,3,9)$.

Our study demonstrated that the increase of AOP and the decrease of HPD correlated with each other and the descent of CFHS. We observed that those sonographic parameters can predict the delivery mode as much as CFHS which is considered the gold standard method for evaluating labor.

In a study that evaluated labor by AOP and HPD together, it was found that $87 \%$ of women, whose AOP measurements were $\geq 110$ degrees and $93 \%$ of those whose HPD measurements were $\leq 40$ millimeters had VD and there was no difference between two and three-dimensional sonography (10). In our study, 110.5 degrees of AOP was the cut off value giving $76 \%$ of AUC. Our findings for AOP were in agreement with prior studies' cut off values which were 120 and 110 degrees. Remarkable correlations between AOP, HPD, and CFHS both during uterine relaxation and contraction were reported (5). However, increase of AOP and decrease of HPD during uterine contraction may be misleading for the prediction of delivery mode and for this reason, these measurements are usually taken during relaxation (11). We took our measurements during the relaxation phase.

Progression of CFHS was prominent while AOP was increasing and HPD was decreasing. Nevertheless there was a broad standard deviation and there were recurrent assessments for CFHS in our study similar to the prior studies $(2,5,12)$. When CFHS was at 0 , AOP was assessed 128 degrees in our investigation however some investigations measure 123, 116 , and 99 degrees of $\operatorname{AOP}(5,12,13,14)$. Because of a wide range of AOP estimates, a case was reported in which AOP was estimated 120 degrees when CFHS was at 0 by magnetic resonance imaging which is the gold standard technique (15).

A study illustrated that the cut off value of HPD prediction of vaginal delivery was 40 millimeters but our results showed that the cut off value was 52.45 millimeters with $74 \%$ AUC (10). Further studies are required due to inconsistency about the HPD's cut off value for the prediction of delivery mode in the literature. Fetal head's HPD, which was at 0, was 40 millimeters in our study. On the other hand, HPD was measured 42 and 36 millimeters when CFHS was at 0 in the previous studies $(5,12)$.

To standardize intrapartum ultrasonography, the routine use of basic parameters can be expanded by adding it to the standard obstetrics training curriculum or integrating it into the partograph. Thus, both more data will be obtained and obstetricians will have practiced.

It was reported that the mean AOP was 131 degrees and the mean HPD 53 millimeters in pregnant women who had VD. In contrast, the mean AOP and HPD were 110 degrees and 61 millimeters, respectively in women who had CD (16). Our mean values in the group of VD were 120 degrees of AOP, 45 millimeters of HPD and in the group of CD were 106 degrees of AOP, 53 millimeters of HPD.

None of the women in this study underwent operative vaginal delivery. We think that three causes may lead to this. The first and most likely reason may be that the study was performed in the low-risk group. Therefore, the indication for operative vaginal delivery was not observed. Second, due to malpractice concerns, obstetricians may avoid operative vaginal delivery. The last reason may be the lack of operative vaginal delivery experience.

It is not surprising that studies performed in prolonged labors have high oxytocin usage rates of $98 \%(10,12)$. In a study performed without the occurrence of dystocia like our study, there was a $70 \%$ oxytocin infusion rate close to our $60.9 \%$ rate $(5)$.

Fetal head engagement in multiparous women occurs in the second stage of labor. Our study confirmed that the mean HPD in multiparous women is longer than in the nulliparous women significantly. AOP is also affected by parity, conversely, this relationship is not statistically significant.

The strengths of our study include the study population being a low-risk obstetric population with a similar incidence of $\mathrm{CD}$ in Turkey and the inclusion of both nulliparous and multiparous women. Intrapartum transperineal ultrasonogra- 
phy was performed methodologically by a single operator, thus avoiding operator variability.

The weakness of the study includes a lack of inter-observer variability due to a single operator. Also, we took measurements only once in labor for practical reasons, in contrast to some of the other published studies. However, single measurements appeared to give similar predictability of the labor outcome to those with multiple measurements.

In conclusion, our findings confirm that intrapartum sonography is a useful diagnostic tool in predicting the labor outcome. It can be used to aid the traditional vaginal examination. When used together, traditional vaginal examination and intrapartum sonography-called sonopartogram-seems to be beneficial $(17,18)$. As an easy to learn, rapid to perform, non-invasive, and low-cost method intrapartum sonography might have a more substantial role in obstetric practice. However, further studies are required to understand the abnormality of labor progress at the early stages and to specify the risk factors that warrant subsequent actions.

Acknowledgment: The authors wish to thank Professor Ertan Saridogan, MD, Ph.D., FRCOG, and consultant at University College London Hospitals, for his suggestion and revision in the arrangement of the article.

Funding: The authors report no financial support.

Author contribution: ES: and OMT: Contributed to the design and implementation of the research, to the analysis of the results, to the writing and revising of the manuscript.

Conflict of interest: The authors report no conflicts of interest.

\section{References}

1. Eggebo TM, Heien C, Okland I, Gjessing LK, Romundstad P, Salvesen KA. Ultrasound assessment of fetal head-perineum distance before induction of labor. Ultrasound Obstet Gynecol. 2008;32(2):199-204. doi: 10. 1002/uog.5360.

2. Barbera AF, Pombar X, Perugino G, Lezotte DC, Hobbins JC. A new method to assess fetal head descent in labor with transperineal ultrasound. Ultrasound Obstet Gynecol. 2009;33(3):313-9. doi: 10.1002/uog.6329.

3. Kalache KD, Dückelmann AM, Michaelis SA, Lange J, Cichon G, Dudenhausen JW. Transperineal ultrasound imaging in prolonged second stage of labor with occipitoanterior presenting fetuses: how well does the 'angle of progression' predict the mode of delivery? Ultrasound Obstet Gynecol. 2009;33(3):326-30. doi: 10.1002/uog. 6294.

4. American College of Obstetricians and Gynecologists; Society for Maternal-Fetal Medicine. Obstetric care consensus no. 1: safe prevention of the primary cesarean delivery. Obstet Gynecol. 2014;123(3):693-711. doi:10. 1097/01.AOG.0000444441.04111.1d.

5. Chan YT, Ng VK, Yung WK, Lo TK, Leung WC, Lau
WL. Relationship between intrapartum transperineal ultrasound measurement of angle of progression and headperineum distance with correlation to conventional clinical parameters of labor progress and time to delivery. J Matern Fetal Neonatal Med. 2015;28(12):1476-81. doi: 10.3109/14767058.2014.958459.

6. Gardberg M, Laakkonen E, Salevaara M. Intrapartum sonography and persistent occiput posterior position: a study of 408 deliveries. Obstet Gynecol. 1998;91:746-9. doi: 10.1016/s0029-7844(98)00074-x.

7. Dietz HP, Lanzarone V. Measuring engagement of the fetal head: validity and reproducibility of a new ultrasound technique. Ultrasound Obstet Gynecol. 2005;25 (2): 165-8. doi: 10.1002/uog.1765.

8. Sherer DM, Abulafia O. Intrapartum assessment of fetal head engagement: comparison between transvaginal digital and transabdominal ultrasound determinations. Ultrasound Obstet Gynecol. 2003;21(5):430-6. doi: 10. 1002/uog.102.

9. Molina FS, Nicolaides KH. Ultrasound in labor and delivery. Fetal Diagn Ther. 2010;27(2):61-7. doi: 10.1159/000 287588.

10. Torkildsen EA, Salvesen KA, Eggebo TM. Prediction of delivery mode with transperineal ultrasound in women with prolonged first stage of labor. Ultrasound Obstet Gynecol. 2011;37(6):702-8. doi: 10.1002/uog.8951.

11. Ghi T, Eggebo T, Lees C, Kalache K, Rozenberg P, Youssef A, et al. ISUOG Practice Guidelines: intrapartum ultrasound. Ultrasound Obstet Gynecol. 2018; 52(1):128-39. doi: 10.1002/uog.19072.

12. Tutschek B, Torkildsen EA, Eggebo TM. Comparison between ultrasound parameters and clinical examination to assess fetal head station in labor. Ultrasound Obstet Gynecol. 2013;41(4):425-9. doi: 10.1002/uog.12422.

13. Tutschek B, Braun T, Chantraine F, Henrich W. A study of progress of labour using intrapartum translabial ultrasound, assessing head station, direction, and angle of descent. BJOG. 2011;118(1):62-9. doi: 10.1111/j.14710528.2010.02775.x.

14. Barbera AF, Imani F, Becker T, Lezotte DC, Hobbins JC. Anatomic relationship between the pubic symphysis and ischial spines and its clinical significance in the assessment of fetal head engagement and station during labor. Ultrasound Obstet Gynecol. 2009;33(3):320-5. doi: 10.10 02/uog.6322.

15. Iliescu D, Tudorache S, Dragusin R, Carbunaru O, Patru C, Florea $\mathrm{M}$, et al. The angle of progression at station 0 and in magnetic resonance and transperineal ultrasound assessment. Case Rep Obstet Gynecol. 2015;2015:74832 7. doi: 10. $1155 / 2015 / 748327$.

16. Gluszak M, Dziadecki W, Wielgos M, Wegrzyn P. Evaluation of sonographic assessment of the progress of labor. Ginekol Pol. 2015;86(2):126-31. doi: 10.17772/gp/ 1999. 
17. Eggebo TM, Wilhelm-Benartzi C, Hassan WA, Usman S, Salvesen KA, Lees CC. A model to predict vaginal delivery in nulliparous women based on maternal characteristics and intrapartum ultrasound. Am J Obstet Gynecol. 2015;213(3):362.e1-6. doi: 10.1016/j.ajog.2015.05.044.
18. Hassan WA, Eggebo T, Ferguson M, Gillett A, Studd J, Pasupathy D, et al. The sonopartogram: a novel method for recording progress of labor by ultrasound. Ultrasound Obstet Gynecol. 2014;43(2):189-94. doi: 10.1002/uog. 13212. 